\title{
A child with congenital factor VII deficiency
}

\author{
M Ranjan ${ }^{1}$, H K Welgama ${ }^{2}$ \\ Sri Lanka Journal of Child Health, 2003; 32: 113-4
}

(Key words: congenital factor VII deficiency, child)

\section{Introduction}

Factor VII (F VII) deficiency is a rare autosomal recessive coagulation disorder with quantitative and qualitative defects ${ }^{1}$. Incidence is $1: 500,000^{2}$. Normal levels of F VII range from $50-150 \% 3$. Homozygotes have F VII concentrations $<10 \%$ whilst heterozygotes have variable levels with a mean $50 \%$ of normal ${ }^{3}$.

Clinical manifestations are variable with poor correlation between circulating F VII coagulant activity and degree of bleeding. Bleeding is frequently of mucocutaneous type. Commonest manifestation is prolonged bleeding following dental extraction. In some neonates bleeding from umbilical stump has been observed. Mild factor VII deficiency patients are asymptomatic and severely affected homozygotes $(<1 \%$ clotting activity) have bleeding similar to haemophilia ${ }^{1}$. Central nervous system bleeding has been reported ${ }^{4}$.

\section{Case report}

An eight year old boy, born of a non-consanguineous marriage, presented with repeated attacks of mucocutaneous bleeding from the age of 3 years after shedding of milk teeth, dental trauma and infrequent ecchymotic patches following minor trauma. His bleeding was controlled with local measures such as applying pressure and an ice pack. There was no past history of liver disease, significant gastrointestinal disease or history of taking oral anticoagulants. He had no family history of bleeding disorders. On examination, he was an averagely grown, otherwise normal, child with a few ecchymotic patches. There was no evidence of anaemia or jaundice and the Hess test was negative.

The haemoglobin was $13.1 \mathrm{~g} / \mathrm{dl}$, white cell count $14 \times 10^{9} / \mathrm{L}(\mathrm{N} 60, \mathrm{~L} 32, \mathrm{E} 8 \%)$ and platelet count 216 $\mathrm{x} 10^{9} / \mathrm{L}$. Blood picture was normocytic,

\footnotetext{
${ }^{1}$ Senior Registrar, ${ }^{2}$ Consultant Paediatrician, Teaching Hospital, Kandy.
}

(Received on 11 April, 2003) normochromic with no abnormal cells. Reticulocyte count was $0.9 \%$. Bleeding time (BT) was $2 \frac{1}{2}$ minutes and clotting time $41 / 2$ minutes. Activated partial thromboplastin time (APTT) was 34 seconds (control 32 seconds) and prothrombin time (PT) 30.7 seconds (control 14.4 seconds). PT was repeated after a 7-day course of vitamin $\mathrm{K}$ therapy and was 37.7 seconds (control 14.4 seconds), PT with addition of plasma was 19.4 seconds and with addition of serum 17.9 seconds. Fibrinogen degradation products were $<2 \mu \mathrm{g} / \mathrm{ml}$ (normal $<10 \mu \mathrm{g} / \mathrm{ml}$ ). Serum protein was 8.5 $\mathrm{g} / \mathrm{dl}$, SGPT $8 \mathrm{IU} / \mathrm{dl}$ (albumin $5.5 \mathrm{~g} / \mathrm{dl}$. globulins 3 $\mathrm{g} / \mathrm{dl})$ and the serum alkaline phosphatase $243 \mathrm{IU} / \mathrm{L}$. Family screening was normal.

\section{Discussion}

Factor VII plays a central role in the initiation of haemostatic response through conceptually divided extrinsic pathway when it forms a complex with tissue factor damaged vessel walls (TF-VIIa) ${ }^{1}$. The TF-VIIa initiates thrombin generation by directly activating the Factor $\mathrm{X}$ and Factor IX. It also activates Factor VII by an autocatalytic mechanism'.

Normal APTT and a prolonged PT that is fully corrected by the addition of normal serum or Russell viper venom signify deficient $F$ VII activity ${ }^{2}$. Congenital F VII deficiency must be differentiated from acquired deficiency as may occur in patients with liver disease vitamin $\mathrm{K}$ deficiency or those on oral anticoagulant therapy and rarely due to circulating inhibitor ${ }^{1}$.

A F VII level $>20 \%$ is considered haemostatic. Products used in F VII deficiency are fresh frozen plasma (FFP), prothrombin complex concentrate (containing Factors II, VII, IX \& X) and a specific F VII concentrate ${ }^{1}$. Excessive

doses of F VII are potentially thrombogenic. Because of varying clinical manifestations of $F$ VII deficiency, replacement therapy should be individualized and will depend on the nature and severity of the coagulation defect, site of bleeding and type of intervention. A plasma level of $10-20 \%$ is sufficient to maintain haemostasis. Infusion of 1 unit 
of FVII concentrate / $\mathrm{kg}$ of body weight increases circulating F VII level by approximately $2 \%$.

In Sri Lanka FFP is the only source of F VII replacement therapy. The dose of FFP is $10-15 \mathrm{ml} / \mathrm{kg}$ and for most bleeding episodes it has to be given 812 hourly.

For treatment of bleeding or as cover for minor surgery, a single dose of F VII concentrate has been found to be sufficient. For surgical interventions it is recommended that a plasma level of $20 \%$ is maintained for 8-10 days. The maintenance dose should be given at intervals of 12 hours ${ }^{1}$. Whereas Jandl suggests administration of replacement therapy 3-4 times daily ${ }^{2}$, Kankirawatana et al observed that FFP had been effective in treatment as well as prophylaxis of intracranial haemorrhage. For prophylaxis they used FFP $10 \mathrm{ml} / \mathrm{kg}$ twice a week ${ }^{4}$.

PT is prolonged with abnormalities of Factors II, X, $\mathrm{V}$ or VII, liver disease, vitamin $\mathrm{K}$ deficiency or if patient is on oral anticoagulants. APTT is prolonged with deficiencies or inhibitors to one or more of the following factors: XII, XI, VIII, X, V, II or I (but not factor VII). Vitamin $\mathrm{K}$ deficiency is usually associated with prolonged PT and APTT.

In our patient the normal platelet count, BT, blood picture and negative Hess test exclude the possibility of platelet or vascular disorders. The PT is prolonged but acquired causes are unlikely as there is no history of liver disease, malabsorption or ingestion of oral anticoagulants. Further, his prolonged PT is accompanied by normal APTT and BT indicating that the defect is in F VII, which could be either of F VII deficiency or inhibitors to FVII. The almost complete correction of PT with normal person's serum and plasma excludes the possibility of an inhibitor. Thus a provisional diagnosis of congenital factor VII deficiency was made, confirmation of which requires F VII assay, which is not possible in our country. The patient was treated with FFP and immunized against hepatitis B virus. Future management plan was drawn up and the parents were instructed accordingly.

\section{Acknowledgements}

We wish to thank Dr. N Ekanayake. Consultant haematologist, Teaching Hospital, Kandy for performing the coagulation profile.

\section{References}

1. Blanchette V S, Dean J, Lillkrap D. Rare congenital hemorrhagic disorders. In: Lilleman J, Hann I Blanchette V, editors. Paediatric Haematology: Edingburgh: Churchill Livingstone, 1999; 619.

2. Jandl J H. Text book of Hematology. 2nd ed. London Churchill Livingstone, 1996 1396-7.

3. De Leo V, Ditto A, Morgante G, La Marca A, et al "Prophylactic therapy in a pregnant woman with severe F VII deficiency." Gynecologic and Obstetric Investigation 2000: 50: 275-7.

4. Kankirawatana S, Mahasandana C, Veerakul G, Seeloem $\mathrm{J}$ et al. "Successful prophylaxis of ICH in infants with severe F VII deficiency." Southeast Asian J Trop Med Public Health 2000; 31 (4): 795-800. 